\title{
A Group-based Dual Trajectory of Depression and Anxiety in Older Adults: An 8-year Follow-up of Population-based Study
}

\author{
Yanzhao Cheng \\ University of Saskatchewan \\ Lilian Thorpe \\ University of Saskatchewan \\ Rasel Kabir \\ University of Saskatchewan \\ Hyun Ja Lim ( $\square$ hyun.lim@usask.ca ) \\ University of Saskatchewan
}

\section{Research Article}

Keywords: depressive disorder, trajectory, anxiety, longitudinal studies, elderly

Posted Date: March 3rd, 2021

DOI: https://doi.org/10.21203/rs.3.rs-263107/v1

License: (c) (i) This work is licensed under a Creative Commons Attribution 4.0 International License. Read Full License 


\section{Abstract}

Background: Depression and anxiety are common mental health conditions for elderly population. Understanding the trajectory developments of them will help us implementing treatments and interventions.

Aims: This study aims to identify depression and anxiety trajectories in the elderly, evaluate the interrelationship of these conditions, and recognize trajectory-predicting characteristics.

Methods: Group-based dual trajectory modeling (GBDTM) was applied to the data of 3,983 individuals, aged 65 years or older who participated in the Korean Health Panel Study between 2008 and 2015. Logistic regression was used to identify the association between characteristics and trajectory groups.

Results: Four trajectory groups from GBDTM were identified in both the depression and anxiety outcomes. Depression has: "low-flat (87.0\%)", "Iowto-middle (8.8\%)", "low-to-high (1.3\%)" and "high-stable (2.8\%)" trajectory groups. Anxiety has: "low-flat (92.5\%)", "low-to-middle (4.7\%)", "high-to-low (2.2\%)" and "high-curve (0.6\%)" trajectory groups. Interrelationship between depression and anxiety were identified. Members of the high-stable depression group were more likely to have "high-to-low" or "high-curved" anxiety trajectories. Female sex, the presence of more than three chronic diseases, and having income generating activity were significant factors in depression and anxiety.

Conclusions: Dual trajectory analysis of depression and anxiety in older adults shows that when one condition is present, the probability of the other is increased. Sex, having more chronic disease, and income generating activity might be at increased risks for both depression and anxiety. Health policy decision-makers can use our findings in developing strategies for prevention of both depression and anxiety in older adults.

\section{Introduction}

Along with the difficulties of aging, elderly individuals are known to be at risk of both depression and anxiety disorders [1]. Recently, research focused on studying the comorbidity of depression and anxiety in elders has increased [2]. One likely reason is the aging population, with the proportion of elderly increasing every year in almost every country [3]. In South Korea, concerns related to aging are substantial, as individuals 65 years or older constitute approximately $14 \%$ of the overall population, more than twice the proportion of people age 14 or younger [4]. Another reason for combined interest in these conditions is that a variety health conditions may influence mental health in the elderly population, potentially generating more than one illness. For example, an elderly person who suffers one or more chronic disease has a greater chance of developing lateonset depression and/or anxiety $[5,6,7]$.

Although it has been suggested that comorbidity between depression and anxiety is less in elders compared to the younger adults [8], it is still of considerable concern. Beekman found that $47.5 \%$ of individuals age 65 years or older who suffer from depression also have a comorbid anxiety disorder [9]. A Korean study included 1204 elderly, showed $22.8 \%$ of them had comorbid anxiety and depression [10]. In terms of psychopathology, elderly patients suffering both conditions simultaneously are regard as more severe cases compared to patients with only one disorder [1]. Depression comorbid with anxiety has been shown to result in more severe somatic symptoms compared to patients with only depression [11, 12]. Moreover, poorer social function and higher suicide rate persist in the comorbid depression and anxiety patient versus the patient with only depression or anxiety $[13,14]$.

The common risk factors for both depression and anxiety in the elderly have been described in three broader categories: biological, psychological and social [15], including the influences of physical illness, disability, bereavement, and others. Nevertheless, longitudinal studies suggest that there are some risk factor differences between elderly depression and anxiety. Among biological risk factors, cognitive functional impairment and visual defect relate to depression but not anxiety, whereas hypertension is risk factor only in anxiety $[9,16,17,18,19,20]$. Also, psychological risk factors have no difference between depression and anxiety $[9,17,20]$. Evaluating social risk factors, marital status and social network size have been correlated with only depression $[21,22,23]$. In contrast, risk factors associated with anxiety but not depression include being childless, traumatic life events, and low income $[9,16,17,18,19,20,24,25]$.

The trajectory analysis of both depression and anxiety were usually developed based on youth and adolescence [26, 27, 28, 29]. To study the trajectory classes in elderly, researchers often focused on only depression [30, 31, 32, 33, 34, 35]. However, depression and anxiety trajectories were rarely studied simultaneously. Only three studies developed the trajectories for both depression and anxiety in elderly [36, 37, 38], while these two studies used separate trajectory models to develop depression and anxiety trajectories. The present study seeks to examine the longitudinal association between depression and anxiety in the elder population with a joint trajectory modeling method. The aims of our study are (i) to describe the trajectories of depression and anxiety, based on heterogeneity, simultaneously for comparison; (ii) to evaluate the relationship between depression and anxiety trajectory groups; and (iii) to identify predictors that may associate with the depression and anxiety trajectory groups.

\section{Methods}

\section{Data and Sample}


This study utilized a subset of a longitudinal survey called the Korea Health Panel Study (KHPS). The KHPS samples, collected by the Korean Institute for Health and Social Affairs in conjunction with the National Health Insurance Service, were selected and weighted from 2005 Korean Population and Housing Census. The KHPS began in 2008 and incorporated a total of 24,616 participants from 7387 households. In 2014 , KHPS was strengthened with the addition of more the 2520 household to mitigate attrition. Using computer assisted personal interviews, trained staff collected the data with three aspect: household, individual, and case-based sections. Comprehensive assessments on the use of healthcare services, cost of healthcare, and potentially influential factors have been conducted annually since 2008. Further details of the KHPS administration and mission are available on the KHPS website [39].

Overall, 3983 elderly who were 65 or older were studied. The additional subjects in year 2014 and 215 were moved to year 2008 and 2009 . The follow-up participation rates among this study's sample were $91.0 \%, 63.4 \%, 60.6 \%, 56.5 \%, 53.4 \%, 50.0 \%$ and $46.4 \%$ from year 2009 to 2015 , respectively. The average number of responses was 5.2 times.

\section{Measures}

The data collection methods for the KHPS involved the investigators visiting the target households and using computer-assisted personal interviewing (CAPI) technique.

Covariates included sex, age, education, marital status, residential area, number of members in the household, household composition type, housing type, current chronic disease status, private health insurance, household income quantile, and household expense. The main dichotomous outcomes of depression and anxiety were collected from medical expenses, including prescription drug receipts or medical institutions/pharmacies, potentially leading to inadequate recognition of our sample outcomes. If there is any annually using of inpatient treatment, outpatient treatment, or emergencyservice utilization from the case-based survey relevant to depression or anxiety, the outcome is assigned to 1 , otherwise, the outcome is assigned to 0.

\section{Statistical Analysis}

The analysis commenced with basic descriptive statistics to characterize the study sample.

General group-based trajectory modeling (GBTM) with single repeated measurement outcome, also called latent class growth modeling, has the ability to identify unobserved heterogeneous subgroups within the sample population and develop trajectories based on the trends within them [40]. The individuals are placed into the most likely subgroups relying on the largest posterior probability (i.e. the probability that an individual with a particular outcome pattern belongs to a particular group among those suggested by the model) [41]. To estimate the model, maximum likelihood estimation is used, and thus the model has the ability to handle the missing, unbalanced data [42].

Group-based dual trajectory modeling (GBDTM) determines the trajectories of two associated outcomes, such as depression and anxiety in our study [43]. The relationship between the two outcomes has been labeled as "comorbidity" or "heterotypic continuity" [44]. "Comorbidity" recognizes multiple illness states occurring at the same time [45]. "Heterotypic continuity" recognizes that two outcomes may linked within an individual but do not occur simultaneously, introducing the possibly of causality [46]. In GBDTM, the linkage of trajectory groups identified within the respective two associated outcomes relies on the conditional probabilities. For example, since depression and anxiety are diagnosed as co-current events in our study, the conditional probabilities for both depression given anxiety and anxiety given depression were considered [47]. Then, this conditional probability represents the likelihood of a person having depression if anxiety is present, and vice versa [44].

To select the most appropriate number of trajectories, separate GBTM for depression and anxiety with the number of trajectory groups from two to five were tried. All the trajectories from the model were assumes to be linear. Bayesian Information Criterion (BIC) [48], Akaike Information Criterion (AIC) [49], and the average posterior probability [50] were utilized to evaluate the model fit. First, the separate GBTM for depression and anxiety were conducted. Then, based on the result from the separate GBTM, GBDTM was developed. SAS programming 9.4 and Proc Traj package was utilized for trajectory modeling and logistic regression. Significant level of this study was set at $a=0.05$.

\section{Results}

3983 participants, who were age 65 or older from KHPS, were investigated during the study period. In this sample, $57 \%$ were female and the average age at baseline measurement was 72.4 (SD \pm 6$)$ years. Among these participants, $63 \%$ had never received any education or only finished elementary school; $62.5 \%$ lived with their spouse, and $1.6 \%$ lived alone. The majority (83\%) reported that their income level was lower than the median income level of the complete survey sample, and $37 \%$ were still undertaking income generating activities. Only $38.2 \%$ lived in metro-cities, and $57.4 \%$ resided in a detached house.

Based on model selection criteria, four trajectory groups was identified as the best fit for both the depression and anxiety outcomes from GBDTM (Table 1). Duel trajectory modeling, with results for the four trajectory groups specified within each outcome, is presented with depression: "Iow-flat (87.0\%)", "low-to-middle (8.8\%)", "low-to-high (1.3\%)" and "high-stable (2.8\%)" trajectory groups (Figs. 1A) and anxiety "low-flat (92.5\%)", "low-to-

Page $3 / 10$ 
middle (4.7\%)", "high-to-low (2.2\%)" and "high-curved (0.6\%)" trajectory groups (Figs. 1B). The characteristics of the sample are described according to the respective trajectory groups from GBDTM (Tables 2 and 3 ).

Table 1

Goodness of fit to select the optimal number of trajectory group for depression and anxiety

\begin{tabular}{|lllllll|}
\hline \multirow{2}{*}{\begin{tabular}{l} 
Number of trajectories \\
\cline { 2 - 8 }
\end{tabular}} & Depression & \multicolumn{5}{c|}{ Anxiety } \\
\hline 2 & BIC & AIC & PP & BIC & AIC & PP \\
\hline 3 & -2534.8 & -2530.7 & 0 & -1525.8 & -1521.7 & 0 \\
\hline 4 & -2403.8 & -2397.2 & 0 & -1484.2 & -1477.6 & 0 \\
\hline 5 & -2363.7 & -2354.7 & 0.83 & -1476.3 & -1467.2 & 1 \\
\hline BIC = Bayesian information criterion, AIC = Akaike information criterion, PP = Posterior probability \\
\hline
\end{tabular}

Conditional probabilities from GBDTM provided a straightforward view of the association between depression and anxiety in the dual trajectory model. The most likely anxiety trajectory regardless of depression trajectory was low-flat, with probabilities ranging from $95.7 \%$ probability in the low-flat depression group to $68.5 \%$ in the high-stable depression group (Fig. $2 \mathrm{~A}$ ). However, $22.9 \%$ of low-to-middle depression trajectory participants were in the low-to-middle anxiety trajectory group and $21.1 \%$ of the high-stable depression group followed a high-to-low anxiety trajectory; respective proportions for these anxiety trajectories were highest among these respective depression trajectories. Persistent anxiety trajectories (high-curved) were only observed among respondents with low-to-middle or high-stable trajectory depression patterns and in small proportions (Fig. $2 \mathrm{~A}$ ).

From the conditional probability of depression given anxiety (Fig. 2B), the proportions with low-flat depression were again high in the low-flat anxiety group (90.0\%), but less so among the other anxiety trajectories (high-to-low, 56.5\%; low-to-middle, 48.9\%; and high-curved, $23.9 \%$ ). Individuals within the low-to-middle anxiety trajectory were almost as likely to follow a low-to-middle depression trajectory (43.0\%) as a low-stable one (48.9\%).

Similarly, participants in the persistent anxiety group (high-curved) also frequently showed a low-to-middle depression trajectory (59.5\%). Although participants in the high-to-low anxiety group did most often follow a low-flat depression trajectory (56.5\%), the high-stable depression trajectory was also relatively common in this group (27.0\%) and in the high-curved group (16.6\%). The low-to-high depression trajectory was generally infrequent in all the groups $(<4 \%$ in all anxiety trajectories).

Univariate (Table 4 and Table 5) and multivariate logistic regression utilized the low-flat group as reference in both the depression and anxiety trajectory outcomes. In multivariate analyses of depression trajectory groups (Table 6), individuals within the low-to-high depression trajectory were more likely to be in the low-to-middle anxiety trajectory group (OR $=5.80,95 \% \mathrm{Cl}$ : $1.83-19.68$, p-value $=0.005)$ than the low-flat depression group and more likely to be not participating in income generating activity $(\mathrm{OR}=2.79,95 \% \mathrm{Cl}: 1.15-6.80, \mathrm{p}$-value $=0.024)$. Similarly, members of the low-tomiddle depression group were also more likely to be in the low-to-middle anxiety trajectory group $(\mathrm{OR}=9.26,95 \% \mathrm{Cl}$ : $5.63-15.22, \mathrm{p}$-value $<0.0001)$ or the high-curved anxiety trajectory group than the low-flat depression group (OR $=25.91,95 \% \mathrm{Cl}: 7.45-90.15, \mathrm{p}-\mathrm{value}<0.0001)$, be female $(\mathrm{OR}=1.51$, $95 \% \mathrm{Cl}: 1.07-2.12, \mathrm{p}$-value $=0.018)$ and have multiple chronic diseases $(\mathrm{OR}=3.96,95 \% \mathrm{Cl}: 1.83-8.59, \mathrm{p}$-value $=0.0005)$. Participants in the highstable depression trajectory group were more often in the low-to-middle $(\mathrm{OR}=10.65,95 \% \mathrm{Cl}$ : $5.30-21.38, \mathrm{p}$-value $<0.0001)$ or high-curved anxiety trajectories $(\mathrm{OR}=17.31,95 \% \mathrm{Cl}: 3.04-98.68, \mathrm{p}$-value $<0.0001)$ and were more likely to be female $(\mathrm{OR}=1.87,95 \% \mathrm{Cl}: 1.02-3.14, \mathrm{p}$-value $=0.042)$, have multiple chronic diseases $(\mathrm{OR}=4.18,95 \% \mathrm{Cl}$ : $1.01-17.31$, $\mathrm{p}$-value $=0.049)$, and not have income generating activity $(\mathrm{OR}=1.91,95 \% \mathrm{Cl}$ : $1.02-$ 3.59 , p-value $=0.044$ ) than the low-flat depression group.

When anxiety trajectory groups were used as the outcome, the depression trajectory groups were similarly associated with the anxiety trajectories (Table 7). In the multivariate logistic analysis, female sex was an adjusted predictor for low-to-middle anxiety group membership (OR = $1.73,95 \% \mathrm{Cl}$ : $1.09-2.76, \mathrm{p}$-value $=0.021)$ and high-to-low anxiety group membership $(\mathrm{OR}=2.17,95 \% \mathrm{Cl}: 1.28-3.69$, $\mathrm{p}$-value $=0.025)$ versus the low-flat anxiety trajectory. Not taking income generating activity was another predictor of high-to-low anxiety group membership over low-flat membership (OR = $2.17,95 \%$ Cl: $1.28-3.69$, p-value $=0.025)$.

\section{Discussion}

In this longitudinal study, data gathered from the KHPS included 3983 Korea elderly people with potential to receive care for depression and/or anxiety symptoms within an 8 year follow up period. To examine the tendency to suffer these two mental health problems simultaneously, which may change over time, GBDTM was applied to identify trajectories of co-occurring depression and anxiety. Among the four groups recognized for their differing probabilities of depression, a large majority showed no depression and were generally unlikely to experience anxiety concomitantly. However, slightly more than $10 \%$ did experience depression during the follow up period, with most of these individuals showing a gradual increase in depression probability. Among individuals following this trajectory, $20 \%$ also experienced a moderately increase in anxiety risk over time. Regarding anxiety, also recognized to follow four trajectories, the vast majority of respondents did not experience this condition and were also free of

Page $4 / 10$ 
depression, although $5 \%$ again saw a slow increase in anxiety propensity over time. This was accompanied by an increasing depression tendency in just under half the cases. In general, female sex, not taking income generating activity, and membership in a trajectory suggesting risk for the alternate condition independently predicted a more vulnerable risk trajectory than "low-flat" for both depression and anxiety.

Our presentation of four trajectory groups aligns with other depression trajectories studies focused on the elderly [30, 31, 32, 33, 35, 51]. However, researchers have only infrequently identified older adult anxiety trajectories: a six-year cohort study of depression and anxiety trajectories in older adults by Holmes et al, which only involved two trajectories (a stable anxiety trajectory (82\%) and an elevated anxiety trajectory (18\%)) [36] and two studies recognizing three anxiety trajectory groups in older adults [37, 38]. In our study, four anxiety trajectory groups were identified. The anxiety trajectory shapes of these latter studies are different than our study as one focused on depressed older patients and the other on musculoskeletal pain patients.

Among our four depression trajectory groups, no decreasing trajectory was found for depression. The high-stable depression group is thought to have less likelihood of recovery in our older population as this life stage is more likely to include reduced life-satisfaction, low income and living quality, and poor health conditions $[52,53,54]$. The low-to-high depression group had an intense increase in depression occurrence from 2009 to 2013 but only contained 31 older adults. The markedly increased probability may have been precipitated by sudden serious events, such as the loss of spouse, physical incapacity, etc. However, among anxiety trajectories, a declining trajectory and a curved shape trajectory showed evidence of a decreasing risk. One explanation may be a reduction in stressful income generating activity as time going by. A possible second explanation for this observe decline is that individuals adapt or cope to their anxious feeling and no longer seek treatment. A third explanation may be that other more pressing medical conditions emerge, eclipsing anxiety management; as such anxiety may still have been present but not identified [55]. The highcurve anxiety trajectory only involves 13 elderly, which is extremely small. However, since the constant high anxiety probability of these subjects, this group is important and cannot be replaced by other trajectory groups.

The association between depression and anxiety were clearly identified from the conditional probabilities of the trajectories and the logistic regression odds ratios. The current finding that the low-to-high and low-to-middle depression group also had risk of being in the low-to-middle anxiety group suggests that older adults with an increasing trend of depression over time also have a greater chance of increasing anxiety, consistent other research $[56,57]$. Moreover, low-to-middle depression group members made up a high proportion in the high-curved anxiety group, suggesting that older patients who had severe anxiety may suffer mild depression as well. High-stable depression group members were more likely to have anxiety risk following the high-to-low and, less frequently, the high-curved anxiety trajectory; individuals in this particular overlap have serious mental health conditions and require more attention [2]. The association between depression and anxiety status is also supported by the inverse of these findings; individuals in this study who did not have one of the study conditions tended not to have the other also.

Our evaluation of demographic risk factors shows varying alignment with the literature. In the majority of the depression and anxiety studies, sex does have an association with these conditions, suggesting older females generally at greater risk [58, 59]. Our study's findings in this regard are consistent with results from other trajectory studies $[34,35,36,60]$. Nevertheless, other studies have found no sex-specific differences when investigating depression and anxiety $[38,61]$. This inconsistency may be related to different economic circumstances, social cultural factors, psychosocial gender roles, or other population differences. In our study, age was a significant univariate influence of depression only, accordant with [36]. Level of education was not a significant predictor of either outcome, which is consistent with some studies [36, 62, 63], but not others [30, 31, $32,33,34,35,38,64]$. In our study, this lack of relationship may be attributable to the relatively low education level in our respondents overall.

Social factors are also known to influence mental health. Some studies suggest that older adults living along or those having no partner within an isolated social environment have a higher risk of depression or anxiety $[60,65,66,67,68,69]$. However, living alone and marital status did not relate to the outcomes in our study, which is consistent with other studies $[32,33,34,37,70]$. The risk behaviors of smoking or excessive drinking might also increasing the risk of depression and anxiety $[31,32,67,71]$. Nevertheless, this association was not identified in our study or in the work of others $[35,65]$. Studies show that homeownership reduces the risk of depression and anxiety $[65,72]$, but this association did not remain in the multivariate analysis. Income generating activity, however, did predict both depression and anxiety trajectory groups, suggesting that people in later life who were still working and having financial security may have better mental health.

Chronic diseases (heart disease, stroke, diabetes asthma, cancer, arthritis, osteoporosis etc.) are understandably difficult challenges for the elderly that may impact mental health. In studying the relationship between depression, anxiety, and chronic disease, Clarke and Kay reviewed 159 papers between 1995 and 2007, finding that depression was correlated with nearly all chronic diseases [73]. However, anxiety only associated with heart disease, stroke, and diabetes mellitus. Moreover, the depression and anxiety patients who were diagnosed with heart disease, stroke, cancer, and arthritis were difficult to treat [73]. In our study, the older adults who have more than three chronic disease were more likely to develop depression. However, in anxiety trajectory groups, chronic disease was only significant in "high-to-low" group from the univariate analysis, but not in the multivariate analysis. Studies have showed that older adults with physical illness or disability usually positive correlate with depression and anxiety $[65,74,75,76]$, but physical/mental disability were not observed to predict these outcomes in the multivariate analysis.

Several limitations should be considered in this study. First, these outcomes were collected from medical expenses and prescription drug receipts or from medical institutions/pharmacies, potentially leading to inadequate recognition of outcomes in our sample. This is particularly true in the context of other chronic disease conditions [77]. Another limitation was the low prevalence of anxiety across the survey period; this limited predictor

Page 5/10 
evaluation, particularly in the poorly populated trajectories such as the "high-curved" group $(n=13)$. Third, although the current study employed data from a large elderly subsample of the KHPS dataset, around $35 \%$ of the outcome measurements were missing, which might result in bias even though the maximum likelihood estimation and GBDTM were used. Fourth, the variables included in this study did not contain all the potentially important health and psychosocial aspects that may be associated with depression and anxiety, such as stressful life events and social/family support information. And lastly, these observations are all made within the specific cultural context of Korean elderly, which may not be generalizable to all contexts.

In summary, four trajectory groups of both depression and anxiety were generated among the elderly of the KHPS dataset. The large majority of older adults belong to the low-flat trajectory group for both depression (87.0\%) and anxiety (92.5\%), which suggests that most older adults do not identify depression and anxiety as problems. However, among those who do, an interrelationship between these diagnoses, particularly in those with anxiety, is evident from GBDTM. Female sex, the presence of 3 or more chronic diseases, and involvement in income generating activity are additional predictors for a concerning depression trajectory group, and with the exception of chronic diseases, for the anxiety trajectories as well. The findings of this study can be used to assist health policy decision-makers in identifying individuals at risk for comorbid depression and anxiety and aid in devising supports for older individuals at risk of deteriorating mental health.

\section{Declarations}

\section{Ethics approval and consent to participate}

This study does not require ethics approval because the data is publicly available.

\section{Consent for publication}

Not applicable

\section{Availability of data and materials}

The datasets analysed during the current study are available in the Korea Health Panel Study repository: https://www.khp.re.kr:444/eng/main.do.

\section{Competing interests}

The authors declare that they have no competing interests.

\section{Funding}

The authors declare that they have no funding support for this study.

\section{Authors' contributions}

YC performed the statistical analysis and wrote the first draft of the manuscript. RK performed data management. LT provided clinical input to the study. HL conceived the original study idea, lead the study and wrote the manuscript. All authors read and approved the final manuscript.

\section{Acknowledgements}

The authors thank all the study participants for generously joining this survey. The authors also thank all the research staff who did data collection and recruitment of participants. The authors thank the reviewers for their helpful comments.

\section{References}

1. Byrne GJ, Pachana NA. Anxiety and depression in the elderly: do we know any more?. Current opinion in psychiatry. 2010 Nov 1;23(6):504-9.

2. Lenze EJ. Comorbidity of depression and anxiety in the elderly. Current Psychiatry Reports. 2003 Feb 1;5(1):62-7.

3. WPA. World Population Aging. Electronic format 2017. Available at:

https://www.un.org/en/development/desa/population/publications/pdf/ageing/WPA2017_Highlights.pdf. Accessed 16 February 2021.

4. Isabella S. South Korea is aging faster than any other developed country. QUARTZ 2017. Available at: https://qz.com/1066613/south-koreademographic-time-bomb-its-aging-faster-than-any-other-developed-country-with-lowest-birth-rate-of-oecdcountries/\#: :text=A\%20growing\%20trend.\&text=The\%20latest\%20census\%20statistics\%20from,13.6\%25\%20of\%20its\%20total\%20population. Accessed 16 February 2021.

5. DeJean D, Giacomini M, Vanstone M, Brundisini F. Patient experiences of depression and anxiety with chronic disease: a systematic review and qualitative meta-synthesis. Ontario health technology assessment series. 2013;13(16):1.

6. Alexopoulos GS. The vascular depression hypothesis: 10 years later. Biological psychiatry. 2006 Dec 1;60(12):1304-5. 
7. Fattouh N, Hallit S, Salameh P, Choueiry G, Kazour F, Hallit R. Prevalence and factors affecting the level of depression, anxiety, and stress in hospitalized patients with a chronic disease. Perspectives in psychiatric care. 2019 Mar 2;55(4):592-9.

8. Flint AJ. Epidemiology and comorbidity of anxiety disorders in the elderly. The American journal of psychiatry. 1994 May.

9. Beekman AT, De Beurs E, Van Balkom AJ, Deeg DJ, Van Dyck R, Van Tilburg W. Anxiety and depression in later life: co-occurrence and communality of risk factors. American Journal of psychiatry. 2000 Jan 1;157(1):89-95.

10. Kang HJ, Bae KY, Kim SW, Shin HY, Shin IS, Yoon JS, Kim JM. Impact of anxiety and depression on physical health condition and disability in an elderly Korean population. Psychiatry Investigation. 2017 May;14(3):240.

11. Flint AJ, Rifat SL. Two-year outcome of elderly patients with anxious depression. Psychiatry research. 1997 Jan 15;66(1):23-31.

12. Zhu C, Ou L, Geng Q, Zhang M, Ye R, Chen J, Jiang W. Association of somatic symptoms with depression and anxiety in clinical patients of general hospitals in Guangzhou, China. General hospital psychiatry. 2012 Mar 1;34(2):113-20.

13. Lenze EJ, Mulsant BH, Shear MK, Schulberg HC, Dew MA, Begley AE, Pollock BG, Reynolds III CF. Comorbid anxiety disorders in depressed elderly patients. American Journal of Psychiatry. 2000 May 1;157(5):722-8.

14. Norton PJ, Temple SR, Pettit JW. Suicidal ideation and anxiety disorders: elevated risk or artifact of comorbid depression?. Journal of behavior therapy and experimental psychiatry. 2008 Dec 1;39(4):515-25.

15. Vink D, Aartsen MJ, Schoevers RA. Risk factors for anxiety and depression in the elderly: a review. Journal of affective disorders. 2008 Feb 1;106(1-2):29-44.

16. Acierno R, Brady K, Gray M, Kilpatrick DG, Resnick H, Best CL. Psychopathology following interpersonal violence: A comparison of risk factors in older and younger adults. Journal of Clinical Geropsychology. 2002 Jan;8(1):13-23.

17. De Beurs E, Beekman A, Geerlings S, Deeg D, Van Dyck R, Van Tilburg W. On becoming depressed or anxious in late life: similar vulnerability factors but different effects of stressful life events. The British Journal of Psychiatry. 2001 Nov;179(5):426-31.

18. Forsell Y. Predictors for depression, anxiety and psychotic symptoms in a very elderly population: data from a 3-year follow-up study. Social psychiatry and psychiatric epidemiology. 2000 Jun 1;35(6):259-63.

19. Schoevers RA, Deeg DJ, Van Tilburg W, Beekman AT. Depression and generalized anxiety disorder: co-occurrence and longitudinal patterns in elderly patients. The American Journal of Geriatric Psychiatry. 2005 Jan 1;13(1):31-9.

20. Schoevers RA, Beekman AT, Deeg DJ, Jonker C, Tilburg WV. Comorbidity and risk-patterns of depression, generalised anxiety disorder and mixed anxiety-depression in later life: results from the AMSTEL study. International journal of geriatric psychiatry. 2003 Nov;18(11):994-1001.

21. Jang Y, Haley WE, Small BJ, Mortimer JA. The role of mastery and social resources in the associations between disability and depression in later life. The gerontologist. 2002 Dec 1;42(6):807-13.

22. Hybels CF, Blazer DG, Pieper CF. Toward a threshold for subthreshold depression: an analysis of correlates of depression by severity of symptoms using data from an elderly community sample. The Gerontologist. 2001 Jun 1;41(3):357-65.

23. Minicuci N, Maggi S, Pavan M, Enzi G, Crepaldi G. Prevalence rate and correlates of depressive symptoms in older individuals: the Veneto Study. The Journals of Gerontology Series A: Biological Sciences and Medical Sciences. 2002 Mar 1;57(3):M155-61.

24. Heun R, Papassotiropoulos A, Ptok U. Subthreshold depressive and anxiety disorders in the elderly. European Psychiatry. 2000 May;15(3):17382.

25. Russo J, Vitaliano PP, Brewer DD, Katon W, Becker J. Psychiatric disorders in spouse caregivers of care recipients with Alzheimer's disease and matched controls: a diathesis-stress model of psychopathology. Journal of abnormal psychology. 1995 Feb;104(1):197.

26. Côté SM, Boivin M, Liu X, Nagin DS, Zoccolillo M, Tremblay RE. Depression and anxiety symptoms: onset, developmental course and risk factors during early childhood. Journal of Child Psychology and Psychiatry. 2009 Oct;50(10):1201-8.

27. Feng X, Shaw DS, Silk JS. Developmental trajectories of anxiety symptoms among boys across early and middle childhood. Journal of abnormal psychology. 2008 Feb;117(1):32.

28. McLaughlin KA, King K. Developmental trajectories of anxiety and depression in early adolescence. Journal of abnormal child psychology. 2015 Feb;43(2):311-23.

29. Olino TM, Klein DN, Lewinsohn PM, Rohde P, Seeley JR. Latent trajectory classes of depressive and anxiety disorders from adolescence to adulthood: descriptions of classes and associations with risk factors. Comprehensive psychiatry. 2010 May 1;51(3):224-35.

30. Liang J, Xu X, Quiñones AR, Bennett JM, Ye W. Multiple trajectories of depressive symptoms in middle and late life: racial/ethnic variations. Psychology and aging. $2011 \mathrm{Dec} ; 26(4): 761$.

31. Kuo SY, Lin KM, Chen CY, Chuang YL, Chen WJ. Depression trajectories and obesity among the elderly in Taiwan. Psychological medicine. 2011 Aug;41(8):1665-76.

32. Byers AL, Vittinghoff E, Lui LY, Hoang T, Blazer DG, Covinsky KE, Ensrud KE, Cauley JA, Hillier TA, Fredman L, Yaffe K. Twenty-year depressive trajectories among older women. Archives of general psychiatry. 2012 Oct 1;69(10):1073-9.

33. Hsu HC. Group-based trajectories of depressive symptoms and the predictors in the older population. International Journal of Geriatric Psychiatry. 2012 Aug;27(8):854-62. 
34. Montagnier D, Dartigues JF, Rouillon F, Pérès K, Falissard B, Onen F. Ageing and trajectories of depressive symptoms in community-dwelling men and women. International journal of geriatric psychiatry. 2014 Jul;29(7):720-9.

35. Kuchibhatla MN, Fillenbaum GG, Hybels CF, Blazer DG. Trajectory classes of depressive symptoms in a community sample of older adults. Acta Psychiatrica Scandinavica. 2012 Jun;125(6):492-501.

36. Holmes SE, Esterlis I, Mazure CM, Lim YY, Ames D, Rainey-Smith S, Fowler C, Ellis K, Martins RN, Salvado O, Doré V. Trajectories of depressive and anxiety symptoms in older adults: a 6-year prospective cohort study. International journal of geriatric psychiatry. 2018 Feb;33(2):405-13.

37. Rzewuska M, Mallen CD, Strauss VY, Belcher J, Peat G. One-year trajectories of depression and anxiety symptoms in older patients presenting in general practice with musculoskeletal pain: A latent class growth analysis. Journal of psychosomatic research. 2015 Sep 1;79(3):195-201.

38. Spinhoven P, van der Veen DC, Voshaar RO, Comijs HC. Worry and cognitive control predict course trajectories of anxiety in older adults with late-life depression. European Psychiatry. 2017 Jul;44:134-40.

39. KHPS. Korea Health Panel Study 2016. Available at: https://www.khp.re.kr:444/eng/main.do. Accessed 16 February 2021.

40. Nagin DS. Analyzing developmental trajectories: a semiparametric, group-based approach. Psychological methods. 1999 Jun;4(2):139.

41. Huang DY, Lanza HI, Anglin MD. Association between adolescent substance use and obesity in young adulthood: a group-based dual trajectory analysis. Addictive behaviors. 2013 Nov 1;38(11):2653-60.

42. Jones BL, Nagin DS, Roeder K. A SAS procedure based on mixture models for estimating developmental trajectories. Sociological methods \& research. 2001 Feb;29(3):374-93.

43. Nagin DS, Tremblay RE. Analyzing developmental trajectories of distinct but related behaviors: a group-based method. Psychological methods. 2001 Mar;6(1):18.

44. Nagin D. Group-based modeling of development Harvard University Press. Cambridge, Mass. 2005.

45. Kessler RC, McGonagle KA, Zhao S, Nelson CB, Hughes M, Eshleman S, Wittchen HU, Kendler KS. Lifetime and 12-month prevalence of DSM-III-R psychiatric disorders in the United States: results from the National Comorbidity Survey. Archives of general psychiatry. 1994 Jan 1;51(1):8-19.

46. Caspi A, Roberts BW. Personality development across the life course: The argument for change and continuity. Psychological inquiry. 2001 Apr 1;12(2):49-66.

47. Wiesner M, Kim HK. Co-occurring delinquency and depressive symptoms of adolescent boys and girls: a dual trajectory modeling approach. Developmental psychology. 2006 Nov;42(6):1220.

48. Schwarz GJ. The annals of statistics. Estimating the dimension of a model. 1978;6:461-4.

49. Akaıke H. A new look at the statistical model identification. IEEE Trans. Automatic Control. 1974 Dec;19:716-23.

50. Kass RE, Wasserman L. A reference Bayesian test for nested hypotheses and its relationship to the Schwarz criterion. Journal of the american statistical association. 1995 Sep 1;90(431):928-34.

51. Xiang X, Cheng J. Trajectories of major depression in middle-aged and older adults: A population-based study. International journal of geriatric psychiatry. 2019 Oct;34(10):1506-14.

52. Dew MA, Whyte EM, Lenze EJ, Houck PR, Mulsant BH, Pollock BG, Stack JA, Bensasi S, Reynolds III, MD CF. Recovery from major depression in older adults receiving augmentation of antidepressant pharmacotherapy. American Journal of Psychiatry. 2007 Jun;164(6):892-9.

53. You KS, Lee HO, Fitzpatrick JJ, Kim S, Marui E, Lee JS, Cook P. Spirituality, depression, living alone, and perceived health among Korean older adults in the community. Archives of Psychiatric Nursing. 2009 Aug 1;23(4):309-22.

54. Jang Y, Small BJ, Haley WE. Cross-cultural comparability of the Geriatric Depression Scale: comparison between older Koreans and older Americans. Aging \& Mental Health. 2001 Feb 1;5(1):31-7.

55. AAPG. Anxiety and Older Adults: Overcoming Worry and Fear 2019. Available at: https://www.aagponline.org/index.php? src=gendocs\&ref=anxiety. Accessed 17 February 2021.

56. Wetherell JL, Gatz M, Craske MG. Treatment of generalized anxiety disorder in older adults. Journal of consulting and clinical psychology. 2003 Feb;71(1):31.

57. Bassil N, Ghandour A, Grossberg GT. How anxiety presents differently in older adults. Curr Psychiatry. 2011 Mar;10:65-72.

58. McLean CP, Asnaani A, Litz BT, Hofmann SG. Gender differences in anxiety disorders: prevalence, course of illness, comorbidity and burden of illness. Journal of psychiatric research. 2011 Aug 1;45(8):1027-35.

59. Girgus JS, Yang K, Ferri CV. The gender difference in depression: are elderly women at greater risk for depression than elderly men?. Geriatrics. 2017 Dec;2(4):35.

60. El-Gilany AH, Elkhawaga GO, Sarraf BB. Depression and its associated factors among elderly: A community-based study in Egypt. Archives of gerontology and geriatrics. 2018 Jul 1;77:103-7.

61. Taylor MG, Lynch SM. Trajectories of impairment, social support, and depressive symptoms in later life. The Journals of Gerontology Series B: Psychological Sciences and Social Sciences. 2004 Jul 1;59(4):S238-46.

62. Norris FH, Murrell SA. Prior experience as a moderator of disaster impact on anxiety symptoms in older adults. American Journal of Community Psychology. 1988 Oct;16(5):665-83.

Page $8 / 10$ 
63. Hong SI, Hasche L, Bowland S. Structural relationships between social activities and longitudinal trajectories of depression among older adults. The Gerontologist. 2009 Feb 1;49(1):1-1.

64. Andreescu C, Chang CC, Mulsant BH, Ganguli M. Twelve-year depressive symptom trajectories and their predictors in a community sample of older adults. International psychogeriatrics/IPA. 2008 Apr;20(2):221.

65. Kang HJ, Bae KY, Kim SW, Shin IS, Yoon JS, Kim JM. Anxiety symptoms in Korean elderly individuals: a two-year longitudinal community study. International psychogeriatrics. 2016 Mar 1;28(3):423.

66. Chong MY, Chen CC, Tsang HY, Yeh TL, Chen CS, Lee YH, Tang TC, Lo HY. Community study of depression in old age in Taiwan: prevalence, life events and socio-demographic correlates. The British Journal of Psychiatry. 2001 Jan;178(1):29-35.

67. Mehta KM, Simonsick EM, Penninx BW, Schulz R, Rubin SM, Satterfield S, Yaffe K. Prevalence and correlates of anxiety symptoms in wellfunctioning older adults: findings from the health aging and body composition study. Journal of the American Geriatrics Society. 2003 Apr;51(4):499-504.

68. Brown JW, Liang J, Krause N, Akiyama H, Sugisawa H, Fukaya T. Transitions in living arrangements among elders in Japan: does health make a difference?. The Journals of Gerontology Series B: Psychological Sciences and Social Sciences. 2002 Jul 1;57(4):S209-20.

69. Won MR, Choi YJ. Are Koreans prepared for the rapid increase of the single-household elderly? Life satisfaction and depression of the singlehousehold elderly in Korea. The Scientific World Journal. 2013 Oct;2013.

70. Cole MA. Sex and marital status differences in death anxiety. OMEGA-Journal of Death and Dying. 1979 Oct;9(2):139-47.

71. Kirchner JE, Zubritsky C, Cody M, Coakley E, Chen H, Ware JH, Oslin DW, Sanchez HA, Durai UN, Miles KM, Llorente MD. Alcohol consumption among older adults in primary care. Journal of General Internal Medicine. 2007 Jan 1;22(1):92-7.

72. Chiao C, Weng LJ, Botticello AL. Social participation reduces depressive symptoms among older adults: an 18-year longitudinal analysis in Taiwan. BMC public health. 2011 Dec;11(1):1-9.

73. Clarke DM, Currie KC. Depression, anxiety and their relationship with chronic diseases: a review of the epidemiology, risk and treatment evidence. Medical Journal of Australia. 2009 Apr;190:S54-60.

74. Knight BG, Nordhus IH, Satre DD. Psychotherapy with older adults. Handbook of Psychology. 2003 Apr 15:453-68.

75. Brenes GA, Penninx BW, Judd PH, Rockwell E, Sewell DD, Wetherell JL. Anxiety, depression and disability across the lifespan. Aging and Mental Health. 2008 Jan 1;12(1):158-63.

76. Hermans H, Evenhuis HM. Factors associated with depression and anxiety in older adults with intellectual disabilities: results of the healthy ageing and intellectual disabilities study. International journal of geriatric psychiatry. 2013 Jul;28(7):691-9.

77. Manela M, Katona C, Livingston G. How common are the anxiety disorders in old age?. International Journal of Geriatric Psychiatry. 1996 Jan;11(1):65-70.

\section{Tables}

Due to technical limitations, tables (2-7) docx is only available as a download in the Supplemental Files section.

\section{Figures}
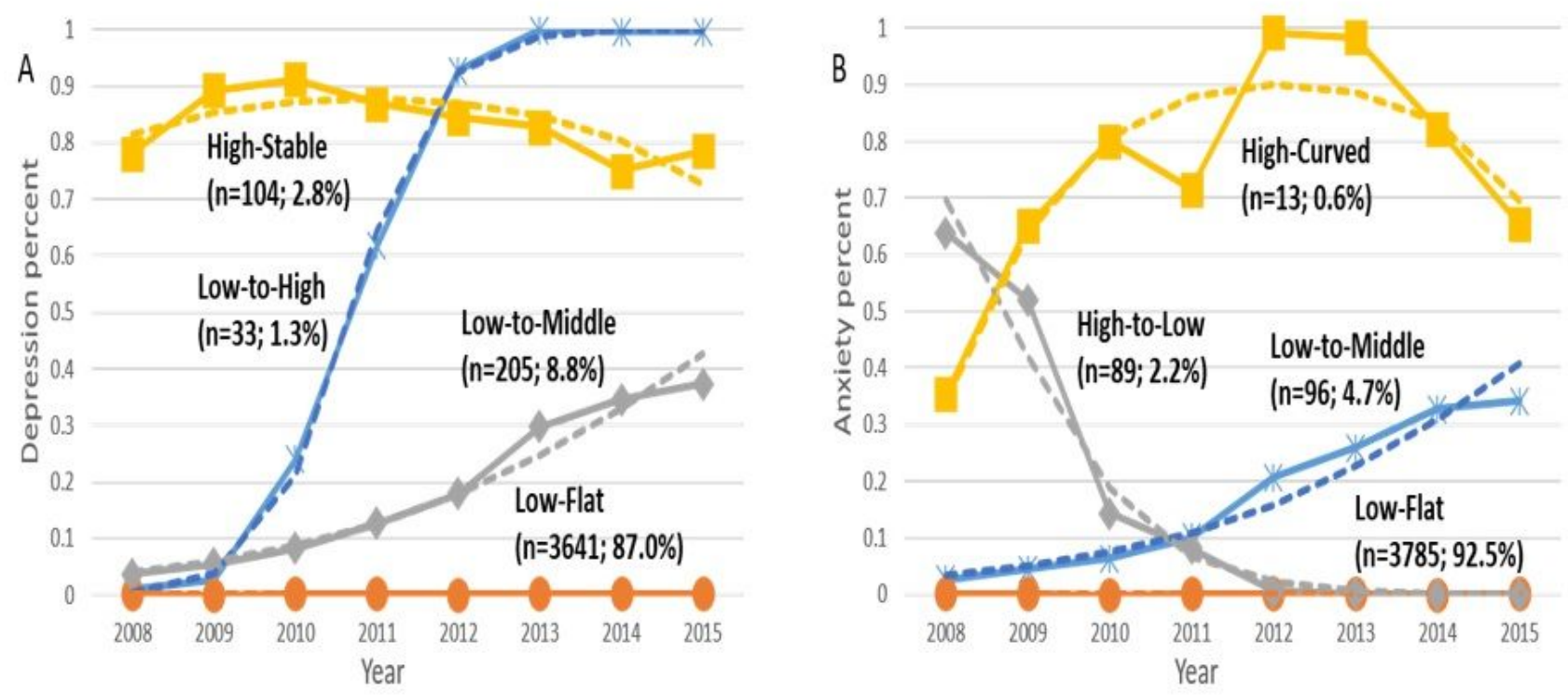

Page $9 / 10$ 
Figure 1

Depression and Anxiety Trajectories. The solid line indicates the observed value; the dot line the dashed line indicates the predicted value. A and B are depression and anxiety trajectories in group-based dual trajectory modeling.
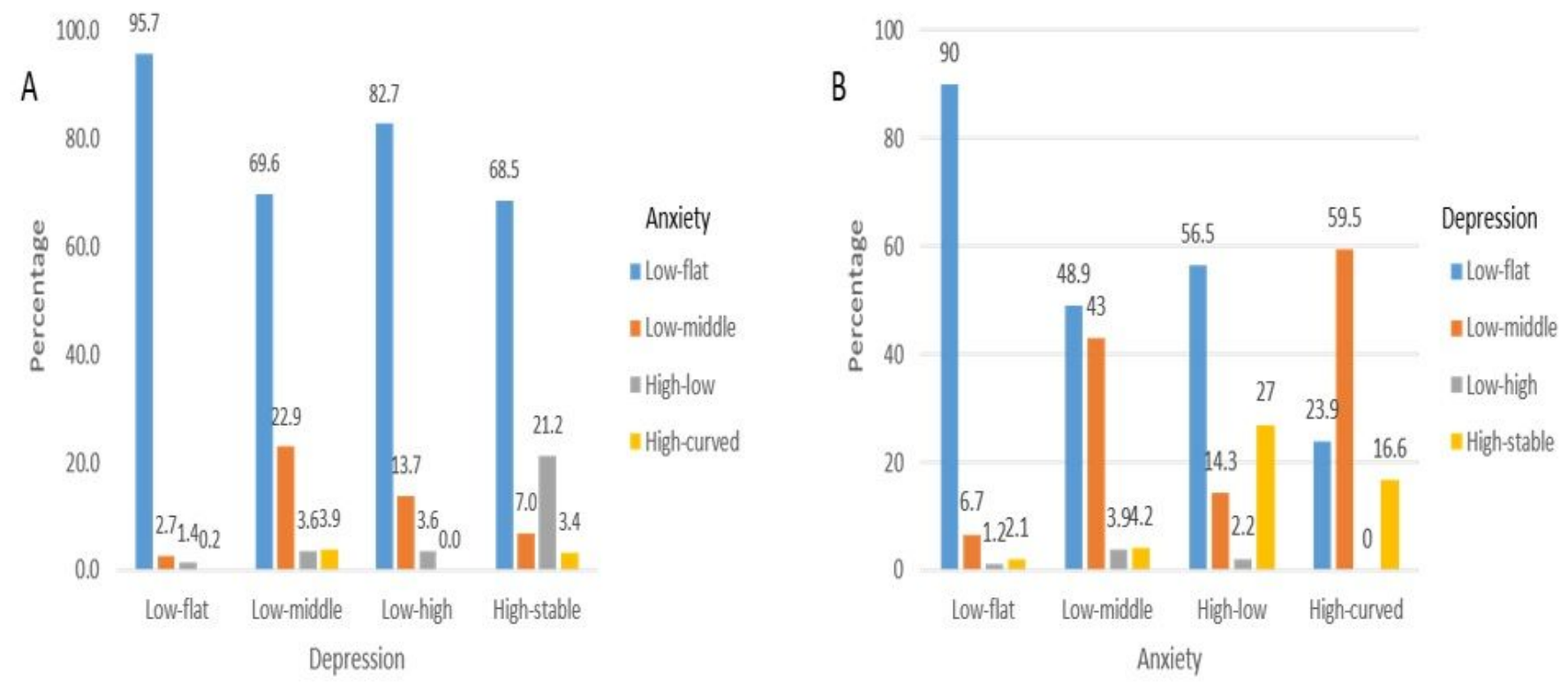

\section{Figure 2}

Conditional probability of anxiety given depression (A). Conditional probability of depression given anxiety (B).

\section{Supplementary Files}

This is a list of supplementary files associated with this preprint. Click to download.

- Tables2to7.docx 